\title{
Prevalence of lifestyle-related cardiovascular risk factors in Peru: the PREVENCION study
}

\author{
Josefina Medina-Lezama, ${ }^{1}$ Oscar L. Morey-Vargas, ${ }^{1}$ Humberto Zea-Díaz, ${ }^{1}$ \\ Juan F. Bolaños-Salazar, ${ }^{1}$ Fernando Corrales-Medina, ${ }^{1}$ Carolina Cuba- \\ Bustinza, ${ }^{1}$ Diana A. Chirinos-Medina, ${ }^{1}$ and Julio A. Chirinos ${ }^{2}$
}

ABSTRACT Objectives. To estimate the prevalence of lifestyle-related cardiovascular risk factors in the adult population of Arequipa, the second largest city in Peru.

Methods. The prevalence and patterns of smoking, alcohol drinking, lack of physical activity, high-fat diet, and low fruit and vegetable intake were evaluated among 1878 subjects (867 men and 1011 women) in a population-based study.

Results. The age-standardized prevalence of current smoking, former smoking, and never smoking were $21.6 \%, 14.3 \%$, and $64.1 \%$, respectively. The prevalence of current smoking was significantly higher in men than women $(31.1 \%$ vs. $12.1 \% ; P<0.01)$. The prevalence of current alcohol use was $37.7 \%$ and significantly higher in men than women (55.5\% vs. $19.7 \%$; $P<0.01)$. Similarly, the prevalence of binge drinking was $21.2 \%$, and the percentage of men who binge drink $(36.1 \%)$ was significantly higher than for women $(6.4 \% ; P<0.01)$. The vast majority of alcohol drinkers reported a pattern of alcohol consumption mainly on weekends and holidays rather than regular drinking with meals during the week. The proportion of insufficiently active people was $57.6 \%$ and was significantly higher in women than men $(63.3 \%$ vs. $51.9 \% ; P<0.01)$. Overall, $42.0 \%$ of adults reported consuming high-fat diets, $34.5 \%$ reported low fruit intake, and $33.3 \%$ reported low vegetable intake.

Conclusions. The high prevalence of lifestyle-related cardiovascular risk factors found in this Andean population is of concern. Preventive programs are urgently needed to deal with this growing problem.

Key words Alcohol drinking, cardiovascular diseases, diet, physical activity, prevalence, risk factors, smoking, Peru.

\footnotetext{
Santa María Catholic University Schools of Medicine and Psychology and Santa María Research Institute, Arequipa, Peru.

2 University of Pennsylvania School of Medicine, Philadelphia, Pennsylvania, United States of America. Send correspondence to: Julio A. Chirinos, Division of Cardiology, 8B111, Philadelphia VA Medical Center, 3900 Woodland Avenue, Philadelphia, PA 19104, U.S.A; telephone: (215) 823-5800, ext. 6791; Fax: (215) 823-4440; e-mail: Julio.chirinos@ uphs.upenn.edu.
}

Cardiovascular diseases (CVD) are now the leading cause of death in most countries of Latin America (1). Although CVD mortality has declined in economically developed nations, growing rates of CVD morbidity and mortality have been observed in developing countries reflecting an epi- demiologic transition characterized by a shift from infectious and deficiency diseases to the preponderance of non-communicable, chronic illnesses (2-8).

The growing rates of CVD seen in recent decades in Latin America have resulted, in large part, from the signif- 
icant changes in lifestyle associated with urbanization and economic development (2-8). Important lifestylerelated cardiovascular risk factors include tobacco use, lack of physical activity, harmful alcohol consumption, and poor dietary patterns. The importance of these risk factors in Latin America has been shown in recent investigations, including the INTERHEART study, where the presence of a healthy lifestyle-avoidance of smoking, regular exercise, and regular fruit and vegetable consumption-was associated with a reduction in the risk of acute myocardial infarction, suggesting that an important proportion of these coronary events could be avoided by lifestyle modifications in the region (9).

We believe that estimates of the prevalence, patterns, and population distribution of cardiovascular risk factors in Andean and other Latin American populations are needed in order to design effective disease prevention programs. In this paper, we report on the findings regarding the prevalence of tobacco and alcohol consumption, lack of physical activity, high-fat diet, and low fruit and vegetable intake in the PREVENCION study, a population-based study of Peruvians (10).

\section{MATERIALS AND METHODS}

\section{Study population}

The general objectives, design, and operation plan of the PREVENCION study have been previously published (10). PREVENCION, the Peruvian study of the prevalence of cardiovascular disease and coronary risk factors (Estudio peruano de prevalencia de enfermedades cardiovasculares), is a population-based study undertaken in Arequipa, the second largest city in Peru. The first phase of PREVENCION was designed to determine the prevalence of CVD and cardiovascular risk factors in the adult study population (10). Arequipa is located in the southern Peruvian Andes at an altitude of 2325 meters. Its population of over 800000 inhabitants live in the urban metropolitan area. The city was considered to be ideal for a study of this nature due to its compact geography, relatively large number of inhabitants, and low number of reference hospitals, facilitating enrollment and prospective follow-up, which is planned for the second phase of the study (10). The population of Arequipa is comparable to other urban populations in Peru and resembles urban populations from Andean countries such as Bolivia and Ecuador. This population consists largely of mestizos, with the degree of admixture being predominantly Andean Amerindian (i.e., autochthonous Quechua and Aymara populations), with small contributions from Spanish whites and minimal contributions from West African populations (11-13).

\section{Sampling design}

Details regarding the sampling strategy have been published (10). The sampling frame for the study was based on Peru's most recent population and household National Census and was provided by the Peruvian National Institute of Statistics and Informatics (10). The sampling strategy was probabilistic, multistage, clustered, and stratified according to geographic location and socioeconomic status. We aimed to enroll a minimum total of 1600 subjects with at least 200 subjects per gender in each pre-defined age group (20-34 years, 35-49 years, 50-64 years, and 65-80 years) to increase statistical power for age-group comparisons. This was achieved through deliberate oversampling of subjects aged $\geq 65$ years old to improve the precision of estimates in these groups. The overall individual response rate was $85.3 \%$ and the final sample consisted of 1878 individuals (867 men and 1011 women) from 626 households enrolled between March 2004 and January 2006. Exclusion criteria included subjects living less than five years in Arequipa, pregnant women, and persons with the diagnosis of any malignant neoplasm.

\section{Interview}

After initial contact with the participants at the household by one of the investigators, a comprehensive evaluation was performed at the study headquarters, including an epidemiologic questionnaire applied by previously trained interviewers (10). The questionnaire assessed basic demographic information, level of education, family health history, personal medical history, and lifestyle behaviors including tobacco smoking, alcohol drinking patterns, physical activity levels, high-fat diet, low fruit intake, and low vegetable intake. Educational level was classified as low (no formal education to completed secondary school) or high (at least one year of post-secondary education). Ethnicity was self-reported. The study was approved by the Santa María Catholic University Human Research Committee, and all participants gave informed consent (10).

\section{Cigarette smoking}

The questionnaire included questions regarding smoking habit and the frequency and quantity of cigarettes consumed by the smokers (14). Subjects were also asked if they were exposed to tobacco smoke at home or at their workplace. Current smokers were defined as those reporting having smoked $\geq 100$ cigarettes during their lifetime and smoking at the time of the survey. Former smokers were defined as those who reported smoking $\geq 100$ cigarettes during their lifetime but who did not smoke at the time of the survey. Never-smokers were defined as those reporting not having smoked $\geq 100$ cigarettes during their lifetime. Current smokers were further categorized as daily (those who smoked at least one cigarette every day) or occasional smokers. Heavy smokers were defined as subjects who smoke $\geq 20$ cigarettes per day. Passive smokers were defined as those who reported exposure to tobacco smoke at home or at their workplace at the time of the survey. 


\section{Alcohol drinking patterns}

All participants were asked about the presence, frequency, quantity, and patterns of alcohol drinking, and the most frequently consumed alcoholic beverage. A drink of alcohol was defined as one can or bottle $(330 \mathrm{~mL})$ of beer, one glass of wine, one cocktail, or a shot of liquor. Current drinkers were defined as those reporting having consumed at least one drink of alcohol within three months prior to the interview. We considered two alcohol drinking patterns: the Anglo-Saxon pattern was defined as drinking alcohol mainly on weekends and holidays, whereas the Mediterranean pattern was defined as regular consumption of alcohol during the week, particularly with meals (15). We also assessed for episodes of binge drinking, defined as the consumption of five or more drinks of alcohol on one occasion for males and as the consumption of four or more drinks of alcohol on one occasion for females $(16,17)$, in the three months prior to the interview. This gender distinction takes into account differences in both weight and metabolism.

\section{Physical activity levels}

The short version of the International Physical Activity Questionnaire (IPAQ) was used to assess physical activity (18). The IPAQ short form is an instrument designed primarily for population surveillance of physical activity among adults. A key feature of this questionnaire is that it can be used in all types of societies, from industrialized to developing nations (18). The IPAQ short form assesses physical activity undertaken in four major domains of day-to-day life: at work (especially if the job involves manual labor), for transport (for example, walking or cycling to work), in domestic duties (e.g., housework or gathering fuel), and in leisure time (e.g., participating in sports or recreational activities) (19). Assessing physical activity in these four domains avoids systematic underestimation in women and individuals from lower socioeconomic status, par- ticularly in developing countries, where occupation and transportation activities represent a substantial proportion of the total activity of individuals. The IPAQ method also has the advantage of being culturally adaptable, allowing changes in examples of activities taking into account a population's customs.

IPAQ assesses physical activity undertaken during the seven days preceding the interview and defines moderate activities as those requiring modest physical effort and producing small increases in respiratory rate for at least 10 minutes of duration, whereas vigorous activities are defined as those requiring hard physical effort and producing large increases in respiratory rate for at least 10 minutes. Following recommendations from the authors of the IPAQ short form (19), we did not apply the questionnaire to individuals older than 69 years old, due to lack of validation data. To assess physical activity levels, we analyzed the answers collected from the questionnaire and, based on international recommendations (20-22), we classified subjects as sufficiently active people if they engaged in moderateintensity activities (including brisk walking) for at least 30 minutes on five or more days per week, or 20 minutes of vigorous-intensity activities on three or more days a week. Those not engaging in these levels of physical activity were classified as insufficiently active.

\section{High-fat diet and low fruit and low vegetable intake}

The MEDFICTS questionnaire was used to assess dietary fat intake (23). This instrument identifies individuals consuming a diet higher in total fat, saturated fat, and cholesterol than currently recommended by the American Heart Association (24, 25). The MEDFICTS questionnaire consists of eight food categories: meats, eggs, dairy, fried foods, fat in baked goods, convenience foods, fats added at the table, and snacks. Within each category, foods are assigned to one of two groups according to their total fat content: group 1 contains higher total fat foods and group 2 contains lower fat choices. Because the majority of highfat foods listed in group 1 also contribute notable amounts of saturated fat and cholesterol, this criterion simplifies the grouping process without sacrificing accuracy (24).

The questionnaire provides options for weekly consumption and approximate serving size of foods eaten within each group and food category. Each food group is given a numeric score based on weekly consumption and serving size. These scores are totaled to obtain a final score, from 0 to 216 points $(23,24)$. Lower MEDFICTS scores indicate diets containing less dietary fat. We considered scores $>38$ points for the identification of subjects consuming high-fat diets that do not meet the population-wide American Heart Association dietary guidelines for fat intake $(24,25)$.

Finally, low fruit intake was defined as the consumption of fruits for less than three days per week (including fresh, canned, dried, or natural fruit juices). Low vegetable intake was defined as the consumption of fresh vegetables for less than three days per week.

\section{Statistical analysis}

Statistical analysis accounted for the complex sampling strategy of the study. Sampling weights were calculated for each subject according to the population distribution. This strategy allowed for accurate point estimates that account for the study design, according to which certain age groups were oversampled to increase statistical power for age group comparisons. Variances were calculated taking the complex sampling design into account, as failure to account for the design effects of a complex sample design will likely result in underestimation of variance (26). Data for continuous variables are presented as means, whereas proportions are presented as frequencies and percentages, with $95 \%$ confidence intervals (CI). All 
tests were two-sided and an alpha level of less than 0.05 was considered to be statistically significant. The complex sample module from SPSS for Windows, version 13 (Chicago, IL) was used for all analyses. Age-standardized estimates presented were calculated according to the standard world population published by the World Health Organization (27). In addition to age-specific prevalence estimates, age-standardized estimates are presented for men and women separately. For standardized estimates in the entire population, a male-to-female ratio of 1:1 was assumed.

\section{RESULTS}

The study sample consisted of 867 (46.2\%) male and 1011 (53.8\%) female subjects. The mean age of the study subjects was 48.5 years for women and 49.6 years for men. Women constituted the majority of the sample, which was apparent for all age groups. The sample consisted predominantly of self-defined mestizos or Amerindians $(92.5 \%)$, with a minor proportion of white $(7.3 \%)$ and black $(0.2 \%)$ subjects. Some important demographic parameters of the study sample are shown in Table 1.

\section{Cigarette smoking}

Overall, the age-standardized prevalence of current smokers, former smokers, and never-smokers were $21.6 \%, 14.3 \%$, and $64.1 \%$, respectively. The prevalence of current smoking was significantly higher in men than women $(31.1 \%$ vs. $12.1 \% ; P<0.01)$. This gender difference was present in all age groups. A decline in the prevalence of current smoking in both genders was observed with increasing age (Table 2). The prevalence of current smoking was significantly higher among those with high $(26.3 \%$; $95 \%$ $\mathrm{CI}=22.9-30.0 \%$ ) than in those with low educational level $(17.2 \% ; 95 \% \mathrm{CI}=$ 14.1\%-20.8\%; $P<0.01)$.

The prevalence of former smoking was $19.7 \%$ in men and $8.9 \%$ in women $(P<0.01)$. There was an evident increase in the proportion of former smokers with increasing age in men but not in women (Table 2). In men, the observed age-related increase in the prevalence of former smoking was proportional to the decrease in current smoking. The prevalence of never-smokers was significantly higher in women $(79.1 \%)$ than men $(49.2 \% ; P<0.01)$, which was true for all age groups studied (Table 2).

TABLE 1. Selected characteristics of a sample of men and women in Arequipa, Peru, 2004-2006

\begin{tabular}{|c|c|c|c|}
\hline & $\begin{array}{l}\text { Men (\%) } \\
(n=867)\end{array}$ & $\begin{array}{l}\text { Women (\%) } \\
(n=1 \quad 011)\end{array}$ & $\begin{array}{l}\text { Overall (\%) } \\
(n=1 \quad 878)\end{array}$ \\
\hline \multicolumn{4}{|l|}{ Age groups } \\
\hline 20-34 years & 24.1 & 24.9 & 24.5 \\
\hline $35-49$ years & 25.6 & 26.9 & 26.3 \\
\hline 50-64 years & 26.5 & 26.5 & 26.5 \\
\hline $65-80$ years & 23.8 & 21.7 & 22.6 \\
\hline \multicolumn{4}{|l|}{ Race/ethnicity ${ }^{a}$} \\
\hline Mestizo ${ }^{\mathrm{b}} /$ Amerindian & 92.5 & 92.5 & 92.5 \\
\hline White & 7.4 & 7.2 & 7.3 \\
\hline Black & 0.1 & 0.3 & 0.2 \\
\hline \multicolumn{4}{|l|}{ Marital status } \\
\hline Married & 68.3 & 57.3 & 62.4 \\
\hline Not married & 31.7 & 42.7 & 37.6 \\
\hline \multicolumn{4}{|l|}{ Educational levelc } \\
\hline High & 52.0 & 44.5 & 48.0 \\
\hline Low & 48.0 & 55.5 & 52.0 \\
\hline
\end{tabular}

The majority of current smokers were occasional smokers $(68.8 \% ; 95 \%$ $\mathrm{CI}=62.5 \%-74.5 \%$ ), the remaining $\mathrm{mi}-$ nority being daily smokers $(31.2 \%$; $95 \% \mathrm{CI}=25.5 \%-37.5 \%)$. A small minority $(2.4 \% ; 95 \% \mathrm{CI}=1.2 \%-4.7 \%)$ of all current smokers were heavy smokers, which represented only $7.9 \%$ (95\% $\mathrm{CI}=4.2 \%-14.6 \%)$ of all daily smokers. The age-standardized prevalence of passive smoking was $31.1 \%(95 \% \mathrm{CI}=$ $27.4 \%-35.0 \%$ ), without significant gender differences.

\section{Alcohol drinking patterns}

Overall, the age-standardized prevalence of current alcohol drinking was $37.7 \%$. The prevalence of current drinking was significantly higher in men than women $(55.5 \%$ vs. $19.7 \%$; $P<$ 0.01), which was true for all age groups (Table 3 ). Younger males (20 to 34 years old) had the highest prevalence of current drinking $(61.5 \%)$. The proportion of current drinkers was significantly higher among those with high $(42.9 \%$; $95 \% \mathrm{CI}=38.9 \%-46.9 \%)$ than in those with low educational level $(33.1 \%$; $95 \%$ CI $=29.6 \%-36.9 \%$; $P<0.01)$.

It is notable that the vast majority $(99.1 \%$; $95 \% \mathrm{CI}=98.3 \%-99.6 \%)$ of current drinkers reported an Anglo-Saxon drinking pattern, whereas only $0.9 \%$ $(95 \%$ CI $=0.4 \%-1.7 \%)$ reported a Mediterranean drinking pattern. Overall, $21.2 \%$ of adults reported binge drinking episodes. The percentage of subjects who reported binge drinking was significantly higher in men $(36.1 \%)$ than women $(6.4 \% ; P<$ $0.01)$, with the highest prevalence observed among men aged 20 to 34 years old (Table 3 ). The majority of current drinkers reported binge drinking $(59.1 \%$; $95 \% \mathrm{CI}=54.2 \%-63.8 \%)$. More than two-thirds of the male current drinkers $(67.4 \%$; $95 \% \mathrm{CI}=61.9 \%$ $72.5 \%)$, and more than one-third of the female current drinkers (35.8\%; 95\% $\mathrm{CI}=27.8 \%-44.8 \%$ ) reported binge drinking episodes.

Among current drinkers, the alcoholic beverage most frequently consumed was beer $(66 \% ; 95 \% \mathrm{CI}=61.1 \%$ - 
TABLE 2. Prevalence of current and former and of persons who never smoked among men and women of different age groups in Arequipa, Peru, 2004-2006

\begin{tabular}{|c|c|c|c|c|c|c|}
\hline \multirow[b]{2}{*}{ Tobacco use / age strata } & \multicolumn{2}{|c|}{ Men } & \multicolumn{2}{|c|}{ Women } & \multicolumn{2}{|c|}{ Overall } \\
\hline & $\%$ & $(95 \% \mathrm{Cl})$ & $\%$ & $(95 \% \mathrm{Cl})$ & $\%$ & $(95 \% \mathrm{Cl})$ \\
\hline \multicolumn{7}{|l|}{ Current $^{\mathrm{a}}$} \\
\hline All subjects (crude) & 32.2 & $(28.4-36.3)$ & 12.6 & $(10.3-15.4)$ & 22.3 & $(19.8-25.0)$ \\
\hline All subjects (age-standardized) & 31.1 & $(27.5-34.9)$ & 12.1 & $(9.9-14.6)$ & 21.6 & (19.3-24.1) \\
\hline Age $20-34$ years & 38.2 & $(31.3-45.6)$ & 15.1 & $(11.2-20.0)$ & 26.5 & $(22.2-31.3)$ \\
\hline Age $35-49$ years & 31.3 & $(25.2-38.2)$ & 14.5 & $(10.4-19.7)$ & 22.7 & $(18.8-27.1)$ \\
\hline Age $50-64$ years & 27.4 & $(21.5-34.3)$ & 8.4 & $(5.6-12.6)$ & 17.9 & $(14.3-22.2)$ \\
\hline Age $65-80$ years & 14.5 & $(10.0-20.4)$ & 2.1 & $(0.9-5.0)$ & 8.2 & $(5.8-11.4)$ \\
\hline \multicolumn{7}{|l|}{ Former ${ }^{b}$} \\
\hline All subjects (crude) & 18.4 & $(15.7-21.5)$ & 8.4 & $(6.6-10.6)$ & 13.4 & $(11.5-15.4)$ \\
\hline All subjects (age-standardized) & 19.7 & $(17.0-22.7)$ & 8.9 & $(7.1-11.0)$ & 14.3 & $(12.5-16.3)$ \\
\hline Age $20-34$ years & 11.4 & $(7.6-16.8)$ & 6.2 & $(3.7-10.1)$ & 8.8 & $(6.1-12.4)$ \\
\hline Age $35-49$ years & 17.6 & $(13.0-23.4)$ & 10.4 & $(7.3-14.7)$ & 13.9 & $(11.0-17.5)$ \\
\hline Age 50-64 years & 27.3 & $(21.7-33.7)$ & 11.0 & $(7.6-15.6)$ & 19.1 & $(15.7-23.0)$ \\
\hline Age $65-80$ years & 39.3 & (32.6-46.5) & 7.6 & $(4.2-13.1)$ & 23.2 & $(19.2-27.8)$ \\
\hline \multicolumn{7}{|l|}{ Neverc } \\
\hline All subjects (crude) & 49.4 & $(45.2-53.6)$ & 79.0 & $(75.7-81.9)$ & 64.4 & $(61.4-67.2)$ \\
\hline All subjects (age-standardized) & 49.2 & $(45.2-53.1)$ & 79.1 & $(76.0-81.9)$ & 64.1 & (61.3-66.9) \\
\hline Age $20-34$ years & 50.4 & $(43.2-57.6)$ & 78.7 & $(73.2-83.4)$ & 64.7 & $(59.6-69.5)$ \\
\hline Age 35-49 years & 51.1 & $(44.1-58.2)$ & 75.1 & $(69.4-80.0)$ & 63.4 & (58.6-67.9) \\
\hline Age 50-64 years & 45.2 & $(38.5-52.1)$ & 80.6 & (75.2-85.0) & 63.1 & (58.2-67.6) \\
\hline Age $65-80$ years & 46.2 & $(39.0-53.6)$ & 90.4 & $(84.8-94.1)$ & 68.6 & (63.7-73.2) \\
\hline
\end{tabular}

a Persons who reported smoking $\geq 100$ cigarettes during their lifetime and at the time of the interview reported smoking daily or on some days.

${ }^{b}$ Persons who reported smoking $\geq 100$ cigarettes during their lifetime but who did not smoke at the time of the interview.

${ }^{c}$ Persons reporting not having smoked $\geq 100$ cigarettes during their lifetime.

TABLE 3. Prevalence of current drinking and binge drinking in men and women of different age groups in Arequipa, Peru, 2004-2006

\begin{tabular}{|c|c|c|c|c|c|c|}
\hline \multirow[b]{2}{*}{ Alcohol use / age strata } & \multicolumn{2}{|c|}{ Men } & \multicolumn{2}{|c|}{ Women } & \multicolumn{2}{|c|}{ Overall } \\
\hline & $\%$ & $(95 \% \mathrm{Cl})$ & $\%$ & $(95 \% \mathrm{Cl})$ & $\%$ & $(95 \% \mathrm{Cl})$ \\
\hline \multicolumn{7}{|l|}{ Current drinking ${ }^{\mathrm{a}}$} \\
\hline All subjects (crude) & 56.7 & $(52.6-60.6)$ & 20.7 & $(17.6-24.2)$ & 38.6 & $(35.7-41.5)$ \\
\hline All subjects (age-standardized) & 55.5 & $(51.7-59.2)$ & 19.7 & $(16.8-22.9)$ & 37.7 & $(35.0-40.4)$ \\
\hline Age $20-34$ years & 61.5 & $(54.5-68.1)$ & 26.5 & $(20.9-32.9)$ & 43.9 & $(39.0-49.0)$ \\
\hline Age $35-49$ years & 59.4 & $(52.3-66.1)$ & 22.2 & $(17.4-28.0)$ & 40.6 & $(35.9-45.5)$ \\
\hline Age $50-64$ years & 48.8 & $(42.3-55.5)$ & 9.4 & $(6.4-13.7)$ & 29.0 & $(24.8-33.5)$ \\
\hline Age $65-80$ years & 38.2 & $(31.4-45.5)$ & 9.5 & $(6.2-14.3)$ & 23.7 & $(19.7-28.2)$ \\
\hline \multicolumn{7}{|l|}{ Binge drinking ${ }^{b}$} \\
\hline All subjects (crude) & 37.2 & $(33.2-41.3)$ & 6.9 & $(5.1-9.2)$ & 21.8 & (19.5-24.3) \\
\hline All subjects (age-standardized) & 36.1 & $(32.4-40.1)$ & 6.4 & $(4.8-8.4)$ & 21.2 & $(19.0-23.6)$ \\
\hline Age $20-34$ years & 42.9 & $(36.0-50.1)$ & 10.2 & $(6.8-14.9)$ & 26.5 & $(22.4-31.0)$ \\
\hline Age $35-49$ years & 37.5 & $(30.8-44.7)$ & 5.8 & $(3.5-9.4)$ & 21.2 & $(17.4-25.6)$ \\
\hline Age 50-64 years & 34.5 & $(28.3-41.3)$ & 1.8 & $(0.7-4.6)$ & 17.8 & $(14.4-21.9)$ \\
\hline Age $65-80$ years & 13.2 & $(8.9-19.2)$ & 5.1 & $(2.8-9.0)$ & 9.1 & $(6.5-12.5)$ \\
\hline
\end{tabular}

a Consumption of at least one drink of alcohol (one can or bottle of beer, one glass of wine, one cocktail or shot of liquor) in the three months prior to the interview.

${ }^{b}$ Consumption of five or more drinks of alcohol on one occasion (men) or four or more drinks of alcohol (women) on one occasion in the three months prior to the interview.

$70.7 \%)$, followed by liquor/spirits (29.8\%; 95\% CI $=25.3 \%-34.8 \%)$, wine $(4 \% ; 95 \% \mathrm{CI}=2.5 \%-6.2 \%)$, and chicha, a fermented maize beverage $(0.2 \%$; $95 \% \mathrm{CI}=0.04 \%-1.0 \%$ ).

\section{Physical activity}

The age-standardized prevalence of insufficient physical activity in the population aged 20 to 69 years old was
$57.6 \%$. The prevalence of insufficient activity was significantly higher in women than men $(63.3 \%$ vs. $51.9 \%$; $P<$ 0.01). The percentage of insufficient physical activity by gender and age 
group is shown in Table 4. Among those with high educational level the proportion with insufficient physical activity was $58.6 \%(95 \% \mathrm{CI}=54.7 \%$ $62.4 \%)$, whereas it was $56.1 \%(95 \%$ $\mathrm{CI}=51.4-60.6 \%)$ in subjects with low educational level. This difference was not statistically significant.

\section{High-fat diet and low fruit and low vegetable intake}

The age-standardized prevalence of high-fat diet consumption was $42.0 \%$, without significant gender differences
(41.0\% among men and $43.1 \%$ among women). The percentage of subjects consuming high-fat diets was highest in men $(46.8 \%)$ and women $(48.7 \%)$ between 20 and 34 years old; it was lowest among men and women who were 65 to 80 years old $(31.7 \%$ and $31.8 \%$, respectively) (Table 5). Analysis by level of education showed that high-fat diet consumption was significantly higher among those with high (46.4\%; 95\% $\mathrm{CI}=42.1 \%-50.9 \%)$ than in those with low educational level $(38.1 \%$; $95 \% \mathrm{CI}=$ $33.8 \%-42.5 \%$; $P<0.05)$.

Overall, the age-standardized prevalence of low fruit intake was $34.5 \%$, without significant gender differences (35.6\% among men and $33.4 \%$ among women). There was an age-related decline in low fruit consumption in both genders (Table 5). Among those with high educational level the proportion of low fruit intake was $33.6 \%(95 \%$ $\mathrm{CI}=29.9 \%-37.4 \%$ ), whereas in subjects with low educational level this proportion was $37.2 \%$ [95\% CI $=33.1 \%$ $41.5 \% ; P=$ NS (not significant)]. The age-standardized prevalence of low vegetable intake was $33.3 \%$. The proportion of low vegetable intake was $35.7 \%$ in men, and $30.8 \%$ in women $(P=\mathrm{NS})$. An age-related decline in low

TABLE 4. Prevalence of insufficient activity in men and women of different age groups in Arequipa, Peru, 2004-2006 a

\begin{tabular}{|c|c|c|c|c|c|c|}
\hline \multirow[b]{2}{*}{ Age group } & \multicolumn{2}{|c|}{ Men } & \multicolumn{2}{|c|}{ Women } & \multicolumn{2}{|c|}{ Overall } \\
\hline & $\%$ & $(95 \% \mathrm{Cl})$ & $\%$ & $(95 \% \mathrm{Cl})$ & $\%$ & $(95 \% \mathrm{Cl})$ \\
\hline Age 20-69 years (crude) & 51.9 & $(47.6-56.2)$ & 63.0 & $(59.1-66.8)$ & 57.6 & $(54.4-60.6)$ \\
\hline Age 20-69 years (age-standardized) & 51.9 & $(47.8-55.9)$ & 63.3 & $(59.6-66.9)$ & 57.6 & $(54.6-60.6)$ \\
\hline Age $20-34$ years & 50.3 & $(43.0-57.5)$ & 62.0 & $(55.5-68.1)$ & 56.2 & $(51.1-61.2)$ \\
\hline Age $35-49$ years & 56.0 & $(49.0-62.8)$ & 61.7 & $(55.5-67.4)$ & 58.9 & (54.1-63.5) \\
\hline Age $50-69$ years & 49.3 & $(43.2-55.3)$ & 67.6 & $(62.1-72.6)$ & 58.6 & $(54.3-62.8)$ \\
\hline
\end{tabular}

a Insufficient activity is defined as not engaging in at least 30 minutes of moderate-intensity activities including brisk walking $\geq 5$ days per week, or 20 minutes of vigorousintensity activities $\geq 3$ days per week.

TABLE 5. Prevalence of high-fat diet, low fruit and low vegetable intake in men and women of different age groups in Arequipa, Peru, 2004-2006

\begin{tabular}{|c|c|c|c|c|c|c|}
\hline & \multicolumn{2}{|c|}{ Men } & \multicolumn{2}{|c|}{ Women } & \multicolumn{2}{|c|}{ Overall } \\
\hline & $\%$ & $(95 \% \mathrm{Cl})$ & $\%$ & $(95 \% \mathrm{Cl})$ & $\%$ & $(95 \% \mathrm{Cl})$ \\
\hline \multicolumn{7}{|l|}{ High-fat diet ${ }^{a}$} \\
\hline All subjects (crude) & 41.9 & $(37.8-46.2)$ & 44.0 & $(39.3-48.7)$ & 42.9 & $(39.5-46.3)$ \\
\hline All subjects (age-standardized) & 41.0 & $(37.1-45.1)$ & 43.1 & $(38.7-47.5)$ & 42.0 & $(38.8-45.3)$ \\
\hline Age $20-34$ years & 46.8 & $(39.7-54.2)$ & 48.7 & $(40.5-57.0)$ & 47.7 & $(42.1-53.4)$ \\
\hline Age $35-49$ years & 44.0 & $(36.6-51.6)$ & 45.7 & $(38.7-52.9)$ & 44.8 & $(39.3-50.4)$ \\
\hline Age $50-64$ years & 31.8 & $(25.4-39.0)$ & 36.5 & $(30.0-43.6)$ & 34.0 & $(29.0-39.3)$ \\
\hline Age $65-80$ years & 31.7 & $(24.7-39.6)$ & 31.8 & $(25.2-39.2)$ & 31.7 & $(26.4-37.5)$ \\
\hline \multicolumn{7}{|l|}{ Low fruit intake ${ }^{b}$} \\
\hline All subjects (crude) & 36.3 & $(32.4-40.4)$ & 34.1 & $(30.5-37.9)$ & 35.2 & $(32.3-38.2)$ \\
\hline All subjects (age-standardized) & 35.6 & $(31.9-39.5)$ & 33.4 & $(30.0-37.1)$ & 34.5 & $(31.7-37.4)$ \\
\hline Age $20-34$ years & 40.6 & $(33.6-48.0)$ & 35.3 & $(29.2-41.8)$ & 37.9 & $(33.1-43.0)$ \\
\hline Age $35-49$ years & 36.1 & $(29.8-43.0)$ & 36.9 & $(31.1-43.1)$ & 36.5 & $(32.0-41.3)$ \\
\hline Age $50-64$ years & 31.9 & $(25.9-38.6)$ & 31.8 & $(26.2-37.9)$ & 31.8 & $(27.4-36.6)$ \\
\hline Age $65-80$ years & 24.3 & $(18.5-31.2)$ & 22.7 & $(17.4-29.2)$ & 23.5 & $(19.2-28.4)$ \\
\hline \multicolumn{7}{|l|}{ Low vegetable intake } \\
\hline All subjects (crude) & 36.5 & $(32.6-40.5)$ & 31.1 & $(27.7-34.8)$ & 33.8 & $(31.0-36.7)$ \\
\hline All subjects (age-standardized) & 35.7 & $(32.1-39.6)$ & 30.8 & $(27.5-34.2)$ & 33.3 & $(30.6-36.1)$ \\
\hline Age $20-34$ years & 40.5 & $(33.8-47.7)$ & 32.9 & $(27.4-38.9)$ & 36.7 & $(32.1-41.5)$ \\
\hline Age $35-49$ years & 35.1 & $(29.0-41.8)$ & 30.6 & $(25.1-36.8)$ & 32.8 & $(28.4-37.6)$ \\
\hline Age 50-64 years & 32.1 & $(26.1-38.8)$ & 28.8 & $(23.7-34.6)$ & 30.5 & (26.2-35.1) \\
\hline Age $65-80$ years & 29.3 & $(23.0-36.5)$ & 28.5 & (22.6-35.3) & 28.9 & $(24.2-34.1)$ \\
\hline
\end{tabular}


vegetable intake was observed specially among men (Table 5). Analysis by level of education showed that low vegetable intake was 31.9\% (95\% $\mathrm{CI}=28.3 \%-35.7 \%$ ) among those with high education, and $36.0 \%$ (95\% CI = $32.1 \%-40.1 \%$; $P=$ NS) in those with low education.

\section{DISCUSSION}

\section{Cigarette smoking}

Smoking is a well-established, major risk factor for CVD as well as for cancer and other serious illness (14). In this study, we found that $21.6 \%$ of adults were current smokers, $14.3 \%$ were former smokers, and $64.1 \%$ never smoked. The prevalence of current smoking was almost three-fold higher in men $(31.1 \%)$ than women (12.1\%), findings that are in line with the significantly higher prevalence of smoking observed in men in many Latin American populations and among Hispanics living in the United States (28-32). According to the $2005 \mathrm{Na}$ tional Health Interview Survey, the overall prevalence of current cigarette smoking among U.S. adults was estimated at $23.9 \%$ for men and $18.1 \%$ for women, whereas the prevalence of current smoking among Hispanics living in the U.S. was $21.1 \%$ in men and $11.1 \%$ in women (32). In Latin America and the Caribbean, the prevalence of current smoking has been estimated to range from $24.1 \%$ (Paraguay) to $66.3 \%$ (Dominican Republic) for men and from 5.5\% (Paraguay) to 26.6\% (Uruguay) for women (30). Although there are important differences in the methodology and definitions of various categories of smoking status used by previous studies in the region, which makes comparisons of smoking prevalence problematic, the available data suggest that Latin America is heterogeneous regarding tobacco use and that the variation in smoking prevalence among countries is considerable (28-31).

The highest prevalence of current smoking in our study was among young adults, and a decrease in the prevalence of current smoking was seen with increasing age in both genders. This decrease, also observed in other Latin American populations and in the U.S. $(29,32)$, may be a consequence of one or a combination of cohort effects (different generations may smoke differently), an increase in the number of persons who quit smoking as they get older, or a survival bias (the premature death of smokers compared to never- and former smokers). We found that in men, the decline in the prevalence of current smoking with increasing age was accounted for by increases in the proportions of former smokers in the older groups. In contrast, among women, the decline in the prevalence of current smoking with increasing age was mainly accounted for by increases in the proportions of never-smokers in the older groups (Table 2). Although our crosssectional results can not quantify survival bias in the study population, they suggest that the decline of current smoking with age in men is largely due to smoking cessation, whereas in women the cohort effect may be more important (meaning that more recent cohorts are adopting tobacco use at a higher rate than did their predecessors). Further studies are required to examine health perceptions related to tobacco use and potentially important determinants of smoking cessation (or lack thereof) in Peruvian men and women, as these culturally related variables may provide important clues for the design of effective smoking cessation and education programs.

In contrast to findings from other populations, where the majority of smokers smoke daily (e.g., in the U.S. more than $80 \%$ of current smokers are daily smokers) (32), only $31.2 \%$ of current smokers were daily smokers in Arequipa. Also, the percentage of heavy smokers was considerably lower $(2.4 \%$ of all current smokers or $7.9 \%$ of daily smokers). We speculate that this smoking pattern is related to economic factors, as it has been observed that the price of cigarettes and the population income are potential factors in varying cigarette consumption levels in other Latin American populations (30). We also found that the proportion of current smokers was significantly higher among those with higher educational level, a group associated with higher income. This suggests that cigarette prices and purchasing power are variables that have an important impact on cigarette consumption in this population.

\section{Alcohol drinking patterns}

We found high levels of alcohol consumption in the study population; overall, more than half of men and around one-fifth of women were current drinkers. We believe that this gender difference may be explained by social and cultural elements present in Latin American populations that make drinking alcohol generally more acceptable for men than for women (33). Although especially high percentages of current drinkers were observed among young adults, alcohol intake was by no means confined to the younger groups. Males between 20 and 34 years old had the highest prevalence of current drinking (61.5\%), and rates remain high among men 35 to 49 years old $(59.4 \%), 50$ to 64 years old $(48.8 \%)$, and 65 to 80 years old (38.2\%). In women, the prevalence of current drinking among those 20 to 34 years old $(26.5 \%)$ and 35 to 49 years old (22.2\%) was comparable, but was substantially lower among those 50 years old and older (around 9\%).

Alcohol consumption is a public health problem in Latin America and the Caribbean, where is it estimated that $4.5 \%$ of all deaths can be attributed to alcohol use (33). In general, in Latin American countries substantial alcohol consumption is observed in the form of irregular, heavy drinking bouts (34). The pattern of alcohol consumption is an important factor to consider when investigating the effects of alcohol on cardiovascular health. An increasing amount of evidence suggests that the effects on cardiovascular health of a pattern of steady, daily alcohol consumption are different from those associated with a pattern of alternating heavy drinking 
and abstinence (35). Epidemiologic studies have consistently associated regular, moderate alcohol drinking with decreased risk of cardiovascular events $(36,37)$. At the same time, acute, heavy, episodic alcohol intake (e.g., binge drinking) appears to be associated with a higher risk of coronary events and mortality (38-40).

Differences in the physiological effects of regular, moderate drinking and binge drinking may explain these findings. A variety of mechanisms have been described by which the moderate intake of alcohol may reduce cardiovascular risk; these include an increase in high-density lipoprotein cholesterol, a decrease in platelet aggregation and coagulation effects, increased fibrinolysis, and beneficial effects on endothelial function (36). There are, however, a number of possible ways by which heavy, episodic alcohol consumption might have negative cardiovascular effects, including induction of ventricular arrhythmias, coronary vasoconstriction, acute elevation of blood pressure, and increased clotting activity $(35,41)$. Binge drinking has also been associated with an increased risk of all types of stroke (particularly in younger men) (42), atrial fibrillation, other forms of arrhythmias, and sudden cardiac death (35). This may be linked to the Saturday, Sunday, and Monday peaks in cardiovascular mortality and morbidity documented in some countries characterized by a high alcohol intake on weekends (43). Many other consequences of binge drinking have especially high social and economic costs, including unintentional injuries, interpersonal violence (e.g., homicide, assault, domestic violence, rape, and child abuse), unsafe sexual practices, unintended pregnancy, child neglect, and lost productivity (44).

We found widespread binge drinking in the Arequipa, Peru, population, particularly in men. The percentage of men who binge drink was $36.1 \%$ (more than two-thirds of male current drinkers), whereas the percentage of women who binge drink was $6.4 \%$ (more than a third of female current drinkers). It is important to note the high proportion of 20 to 34-year-old men who reported binge drinking episodes (42.9\%). Furthermore, our study indicates that the Anglo-Saxon pattern was by far the predominant pattern of alcohol drinking $(99.1 \%)$ and that most of the alcohol consumed comes from beer and spirits. The results presented here indicate that alcohol is consumed mainly during weekends and holidays, usually in the form of binges when beer or spirits are consumed, and that the pattern of daily, moderate drinking associated with protection against CVD is uncommon. Clearly, educational campaigns are required to address the harmful patterns of alcohol use in this population, and further studies in Peru and the rest of Latin America are needed to determine the overall impact of alcohol consumption as a risk factor of CVD.

\section{Physical activity}

There is compelling evidence that physical activity has many important health benefits and that sedentary habits are associated with an increased risk of numerous chronic diseases and decreased longevity (21). Inactivity is recognized as a risk factor for coronary artery disease and cardiovascular mortality, whereas regular physical activity plays a role in both primary and secondary prevention of CVD (22). Physical activity also favorably modifies several CVD risk factors, including obesity, high blood pressure, harmful lipid patterns, and insulin resistance (22). The U.S. Department of Health and Human Services recommends that adults should engage in at least 30 minutes of moderate-intensity activity on 5 or more days per week, or 20 minutes of vigorous-intensity activity on 3 or more days per week (20), with additional health and fitness benefits deriving from becoming more physically active or including more vigorous activities (21). However, despite the known health benefits of regular physical activity and communitywide campaigns, more than half of U.S. adults do not engage in the minimum recommended activity levels
(45). The few studies that have quantified physical activity in Latin American countries also document high rates of sedentary lifestyle $(29,46-48)$.

Lack of comparability has been a major limitation in studies on physical activity, mostly due to the use of different methodological instruments. In order to minimize this problem, a standardized International Physical Activity Questionnaire (IPAQ) has been proposed as an instrument for cross-national monitoring of physical activity and inactivity (18). A key feature of this particular questionnaire is that it can be used in all types of societies, from industrialized nations to developing countries.

Our findings in the Arequipa population indicate that the majority $(57.6 \%)$ of adults aged 20 to 69 years do not engage in the internationally recommended levels of physical activity. We found that the prevalence of insufficient activity was higher for women than for men, probably reflecting gender differences mainly in activities relating to work and leisure time. Like other studies evaluating the four major domains of physical activity $(46,47)$, and unlike studies evaluating only leisure time activity, our data did not show an association between insufficient activity and age (Table 4).

Comparable data from populationbased studies that have used the IPAQ survey questions in Latin America are limited. Matsudo et al. (46) reported overall prevalence of insufficient activity of $46.5 \%$ in São Paulo, Brazil. The age-specific percentages of insufficient activity in the São Paulo sample were $43.7 \%, 48.6 \%$, and $46.4 \%$ for subjects 15-29 years old, 30-49 years old, and 50-69 years old, respectively. These values are lower than the age-specific percentages reported in our study (Table 4). In a population-based survey of adult residents of Bogotá, Colombia, Gómez et al. found overall prevalence of insufficient activity of $63.2 \%$ (48). The age-specific prevalence rates in Bogotá of insufficient activity were $59.9 \%, 64.1 \%$, and $69.0 \%$ for subjects 18-29 years old, 30-49 years old, and 50-65 years old, respectively (values higher than those found in our 
study). These data indicate that low levels of physical activity are already a serious problem in urban areas of the region and that some variations in the prevalence of insufficient activity exist in different cities of Latin America.

\section{High-fat diet and low fruit and low vegetable intake}

Epidemiologic studies have shown that people that consume high amounts of saturated fatty acids and cholesterol have an increased risk of developing CVD, mostly by modulating plasma lipoprotein concentrations (49). Total fat and saturated fat intake has increased dramatically in Latin America $(50,51)$. Populations in South America's Southern Cone, which have traditionally obtained around $25 \%$ of the total energy supply from fats, approached a level of 30\% by the 1990s. Brazil had the most rapid increase, from just over $16 \%$ to about $28 \%$ in 30 years. In the Andean region there has also been an increase in fat intake, from about $18 \%$ of total energy during the 1960s to about $24 \%$ during the 1990s. These data are based on country data from the Food and Agriculture Organization of the United Nations food balance sheets for the period 1964-1996 (51).
We found that an important percentage $(42 \%)$ of adults in Arequipa reported consuming high-fat diets, which tended to decrease with increasing age. Many possible factors that need further investigation may explain this last finding (e.g., prevalence of chronic diseases that are managed with low-fat diets is higher in the older age groups, different generational diet preferences, survival bias, among others). Interestingly, the proportion of high-fat diet consumption was significantly higher among those with high educational level, probably reflecting cultural and economic variables present in different social strata of this population. Finally, more than onethird of subjects reported consuming fruits or fresh vegetables less than three days per week. This is a troubling finding considering that fruits and vegetables are important components of a healthy diet, and that sufficient daily consumption could help prevent major diseases such as certain cancers and CVD (51).

The findings of the study are subject to certain limitations. The results were based on self-report, and thus the prevalence observed may have been affected by recall bias. Estimates for cigarette smoking were not validated by biochemical tests. As in other popula- tion studies, self-reported use of alcohol is likely to underestimate the real consumption level. Over-reporting of physical activity using the IPAQ instrument has been previously reported and this could also be a problem in our study, particularly among the older age groups (52).

\section{Conclusions}

We report alarmingly high prevalence rates of tobacco smoking, harmful alcohol consumption patterns, insufficient physical activity, high-fat diets, and low fruit and low vegetable intake in this Andean population, along with detailed data on the population distribution of these cardiovascular risk factors. Control programs for CVD risk factors that include systematic surveillance and the adoption of multiple intervention strategies are urgently needed to deal with this growing problem. Data such as that provided here will aid in the design of programs to prevent CVD in Peru and the Andean region.

Acknowledgments. We are indebted to the Peruvian National Institute of Statistics and Informatics for their support with this project.

\section{REFERENCES}

1. Barceló A. Cardiovascular diseases in Latin America and the Caribbean. Lancet. 2006;368(9536):625-26.

2. Reddy KS, Yusuf S. Emerging epidemic of cardiovascular disease in developing countries. Circulation. 1998;97(6):596-601.

3. Chavez DR. Issues and challenges for CVD prevention in Ibero-America: the challenge of human resource development. Can J Cardiol. 1993;9(Suppl D):195D-196D.

4. Medina-Lezama J, Chirinos JA, ChirinosPacheco J. Cardiovascular disease in Latin America. Am Heart J. 2005;149(2):E13.

5. Omran AR. The epidemiologic transition: a theory of the epidemiology of population change. Milibank Mem Fund Q. 1971;49(4): 509-38.

6. Frenk J, Lozano R, Bobadilla JL. The epidemiological transition in Latin America. Notas Población. 1994;22(60):79-101.
7. Popkin BM. The nutrition transition in lowincome countries: an emerging crisis. Nutr Rev. 1994;52(9):285-98.

8. Yusuf S, Reddy S, Ounpuu S, Anand S. Global burden of cardiovascular diseases: part I: general considerations, the epidemiologic transition, risk factors, and impact of urbanization. Circulation. 2001;104(22):2746-53.

9. Lanas F, Avezum A, Bautista LE, Diaz R, Luna M, Islam S, et al. Risk factors for acute myocardial infarction in Latin America: the INTERHEART Latin American study. Circulation. 2007;115(9):1067-74.

10. Medina-Lezama J, Chirinos JA, Zea Díaz H, Morey O, Bolanos JF, Munoz-Atahualpa E, et al. Design of PREVENCION: a populationbased study of cardiovascular disease in Peru. Int J Cardiol. 2005;105(2):198-202.

11. Rodriguez-Delfin LA, Rubin-de-Celis VE, Zago MA. Genetic diversity in an Andean population from Peru and regional migration patterns of Amerindians in South America: data from $Y$ chromosome and mitochondrial DNA. Hum Hered. 2001;51(1-2):97-106.

12. Modiano G, Bernini L, Carter ND, Santachiara-Benerecetti AS, Setter JC, Baur EW, et al. A survey of several red cell and serum genetic markers in a Peruvian population. Am J Hum Genet. 1972;24(2):111-23.

13. Brutsaert TD, Parra E, Shriver M, Gamboa A, Palacios J, Rivera M, et al. Effects of birthplace and individual genetic admixture on lung volume and exercise phenotypes of Peruvian Quechua. Am J Phys Anthropol. 2004;123(4): 390-8.

14. World Health Organization (WHO). Guidelines for controlling and monitoring the tobacco epidemic. Geneva: WHO; 1998.

15. Rehm J, Rehn N, Room R, Monteiro M, Gmel $\mathrm{G}$, Jernigan $\mathrm{D}$, et al. The global distribution of 
average volume of alcohol consumption and patterns of drinking. Eur Addict Res. 2003; 9(4):147-56.

16. Wechsler $\mathrm{H}$, Isaac N. Binge drinkers at Massachusetts colleges; prevalence, drinking style, time trends, and associated problems. JAMA. 1992;267(21):2929-31.

17. Wechsler H, Nelson TF. Binge drinking and the American college student: what's five drinks? Psychol Addict Behav. 2001;15(4): 287-91.

18. Craig CL, Marshall AL, Sjöström M, Bauman $\mathrm{AE}$, Booth ML, Ainsworth BE, et al. International Physical Activity Questionnaire (IPAQ): 12-country reliability and validity. Med Sci Sports Exerc. 2003;35(8):1381-95.

19. Guidelines for data processing and analysis of the International Physical Activity Questionnaire (IPAQ)-short and long forms (November 2005) [Internet site]. Available from: www.ipaq.ki.se/scoring.pdf. Accessed 4 November 2006.

20. U.S. Department of Health and Human Services. Healthy people 2010. 2nd ed. Washington, D.C.: U. S. Government Printing Office; 2000.

21. Pate RR, Pratt M, Blair SN, Haskell WL, Macera CA, Bouchard C, et al. Physical activity and public health. A recommendation from the Centers for Disease Control and Prevention and the American College of Sports Medicine. JAMA. 1995;273(5)402-7.

22. NIH Consensus Development Panel on Physical Activity and Cardiovascular Health. Physical activity and cardiovascular health. JAMA. 1996; 276(3): 241-246.

23. National Cholesterol Education Program (NCEP) Expert Panel on Detection, Evaluation, and Treatment of High Blood Cholesterol in Adults (Adult Treatment Panel III). Third Report of the National Cholesterol Education Program (NCEP) Expert Panel on Detection, Evaluation, and Treatment of High Blood Cholesterol in Adults (Adult Treatment Panel III), final report. Circulation. 2002; 106(25):3143-421.

24. Taylor AJ, Wong H, Wish K, Carrow J, Bell D, Bindeman J, et al. Validation of the MEDFICTS dietary questionnaire: a clinical tool to assess adherence to American Heart Association dietary fat intake guidelines. Nutr J. 2003;2(1):4.

25. Krauss RM, Eckel RH, Howard B, Appel LJ, Daniels SR, Deckelbaum RJ, et al. AHA dietary guidelines: revision 2000: A statement for healthcare professionals from the Nutrition Committee of the American Heart Association. Circulation. 2000;102(18):2284-99.

26. Krewski D, Rao JNK. Inference from stratified samples: properties of the linearization, jackknife, and balanced repeated replication methods. Ann Stat. 1981;9(5):1010-19.

27. Ahmad OB, Boschi-Pinto C, Lopez AD, Murray $C J L$, Lozano $R$, Inoue $M$. Age standard- ization of rates: a new WHO standard. GPE Discussion Paper Series: No. 31. Geneva: World Health Organization; 2006.

28. Bautista LE, Orostegui M, Vera LM, Prada GE, Orozco LC, Herran OF. Prevalence and impact of cardiovascular risk factors in $\mathrm{Bu}-$ caramanga, Colombia: results from the Countrywide Integrated Noncommunicable Disease Intervention Programme (CINDI/ CARMEN) baseline survey. Eur J Cardiovasc Prev Rehabil. 2006;13(5)769-75.

29. Jadue L, Vega J, Escobar MC, Delgado I, Garrido C, Lastra P, et al. Risk factors for noncommunicable diseases: methods and global results of the CARMEN program basal survey. Rev Med Chil. 1999;127(8):1004-13.

30. da Costa e Silva VL, Koifman S. Smoking in Latin America: a major public health problem. Cad Saude Publica. 1998;14(Suppl 3):99S-108S.

31. United States Department of Health and Human Services (U.S. DHHS). Smoking and health in the Americas. Atlanta, Georgia: U.S. DHHS; 1992.

32. Centers for Disease Control and Prevention (CDC). Tobacco use among adults-United States, 2005. MMWR Morb Mortal Wkly Rep. 2006;55(42):1145-8.

33. Pyne HH, Claeson M, Correia M. Gender dimensions of alcohol consumption and alcohol-related problems in Latin America and the Caribbean. Washington, D.C.: International Bank for Reconstruction and Development/The World Bank; 2002. (World Bank Discussion Paper No. 433).

34. Rehm J, Monteiro M. Alcohol consumption and burden of disease in the Americas: implications for alcohol policy. Rev Panam Salud Publica. 2005;18(4-5):241-8.

35. Puddey IB, Rakic V, Dimmitt SB, Beilin LJ. Influence of pattern of drinking on cardiovascular disease and cardiovascular risk factors-a review. Addiction. 1999;94(5):649-63.

36. Pearson TA. Alcohol and heart disease. Circulation. 1996;94(11):3023-5.

37. Corrao G, Rubbiati L, Bagnardi V, Zambon A, Poikolainen K. Alcohol and coronary heart disease: a meta-analysis. Addiction. 2000;95(10): 1505-23.

38. McElduff P, Dobson AJ. How much alcohol and how often? Population based case-control study of alcohol consumption and risk of a major coronary event. BMJ. 1997;314(7088): 1159-64.

39. Kauhanen J, Kaplan GA, Goldberg DE, Salonen JT. Beer binging and mortality: results from the Kuopio ischaemic heart disease risk factor study, a prospective population based study. BMJ. 1997;315(7112):846-51.

40. Mukamal KJ, Maclure M, Muller JE, Mittleman MA. Binge drinking and mortality after acute myocardial infarction. Circulation. 2005;112(25):3839-45

41. McKee M, Britton A. The positive relationship between alcohol and heart disease in
Eastern Europe: potential physiological mechanism. J R Soc Med. 1998;91(8):402-7.

42. Mazzaglia G, Britton AR, Altmann DR, Chenet L. Exploring the relationship between alcohol consumption and non-fatal or fatal stroke: a systematic review. Addiction. 2001 96(12):1743-56.

43. Evans C, Chalmers J, Capewell S, Redpath A, Finlayson A, Boyd J, et al. "I don't like Mondays"-day of the week of coronary heart disease deaths in Scotland: study of routinely collected data. BMJ. 2000;320(7229): 218-9.

44. Naimi TS, Brewer RD, Mokdad A, Denny C, Serdula MK, Marks JS. Binge drinking among US adults. JAMA. 2003;289(1):70-5.

45. Centers for Disease Control and Prevention (CDC). Adult participation in recommended levels of physical activity-United States, 2001 and 2003. MMWR Morb Mortal Wkly Rep. 2005;54(47):1208-12.

46. Matsudo S, Matsudo V, Araújo T, Andrade D Andrade E, Oliveira L, et al. Nível de atividade física da população do Estado de São Paulo: análise de acordo com o gênero, idade, nível sócio-econômico, distribuição geográfica e de conhecimento. Rev Bras Ciênc Mov. 2002;10(4):41-50.

47. Hallal PC, Victora CG, Wells JC, Lima RC Physical inactivity: prevalence and associated variables in Brazilian adults. Med Sci Sports Exerc. 2003;35(11):1894-1900.

48. Gómez LF, Duperly J, Lucumí DI, Gámez R, Venegas AS. Physical activity levels in adults living in Bogotá (Colombia): prevalence and factors associated. Gac Sanit. 2005;19(3): 206-13.

49. Shekelle RB, Stamler J. Dietary cholesterol and ischaemic heart disease. Lancet. 1989; 1(8648):1177-9

50. Bermudez OI, Tucker KL. Trends in dietary patterns of Latin American populations. Cad Saude Publica. 2003;19(Suppl 1):S87-S99.

51. World Health Organization (WHO) and Food and Agriculture Organization of the United Nations (FAO). Diet, nutrition and the prevention of chronic diseases. Report of a Joint WHO/FAO Expert Consultation. Geneva: WHO; 2003. (WHO Technical Report Series 916).

52. Rzewnicki R, Vanden Auweele Y, De Bourdeaudhuij I. Addressing overreporting on the International Physical Activity Questionnaire (IPAQ) telephone survey with a population sample. Public Health Nutr. 2003;6(3): 299-305.

Manuscript received on 6 June 2007. Revised version accepted for publication on 21 April 2008. 
RESUMEN Objetivos. Estimar la prevalencia de factores de riesgo cardiovascular relacionados con el estilo de vida de adultos de Arequipa, la segunda mayor ciudad de Perú.

\section{Prevalencia de factores de riesgo cardiovascular relacionados con el estilo de vida en Perú: el estudio PREVENCIÓN}

Métodos. Se realizó un estudio de base poblacional para evaluar la prevalencia y los patrones de consumo de tabaco y bebidas alcohólicas, la falta de actividad física, la dieta rica en grasas y el bajo consumo de frutas y vegetales en 1878 personas (867 hombres y 1011 mujeres).

Resultados. Las prevalencias estandarizadas por la edad de los fumadores actuales, pasados y de los que nunca fumaron fueron $21,6 \%, 14,3 \%$ y $64,1 \%$, respectivamente. La prevalencia de tabaquismo fue significativamente mayor en los hombres que en las mujeres $(31,1 \%$ frente a $12,1 \% ; P<0,01)$. La prevalencia del consumo de bebidas alcohólicas fue de $37,7 \%$, significativamente mayor en los hombres que en las mujeres (55,5\% frente a $19,7 \% ; P<0,01)$. La prevalencia del consumo excesivo de alcohol fue de $21,1 \%$, mayor en los hombres que en las mujeres $(36,1 \%$ frente a $6,4 \% ; P<0,01)$. La gran mayoría de los bebedores presentó un patrón de consumo concentrado fundamentalmente en los fines de semana y los días feriados, más que el consumo habitual con las comidas en los días laborables. La proporción de personas con insuficiente actividad fue de $57,6 \%$, significativamente mayor en las mujeres que en los hombres $(63,3 \%$ frente a $51,9 \% ; P<0,01)$. En general, $42,0 \%$ de los adultos informaron consumir dietas ricas en grasas, $34,5 \%$ dijo tener un bajo consumo de frutas y $33,3 \%$ un bajo consumo de vegetales.

Conclusiones. La alta prevalencia de factores de riesgo cardiovascular relacionados con el estilo de vida encontrada en esta población de los Andes es preocupante. Se deben implementar urgentemente programas preventivos para resolver este creciente problema.

Palabras clave Consumo de bebidas alcohólicas, enfermedades cardiovasculares, dieta, actividad física, prevalencia, factores de riesgo, tabaquismo, Perú. 